\title{
REPORT
}

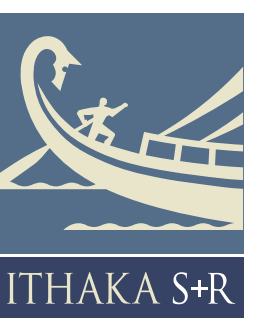

\section{Supporting the Changing Research Practices of Agriculture Scholars}

June 7, 2017

Danielle Cooper

$\begin{array}{lll}\text { Sarah Bankston } & \text { Marei Houpert } & \text { Necia Parker-Gibson } \\ \text { Marianne Stowell Bracke } & \text { Claudine ArnoldJenda } & \text { Cynthia Parr } \\ \text { Beth Callahan } & \text { Erin Kerby } & \text { Hannah Gascho Rempel } \\ \text { Hui-Fen Chang } & \text { Megan Kocher } & \text { M.Brooke Robertshaw } \\ \text { Leslie M. Delserone } & \text { Adam Kriesberg } & \text { Ashley Shea } \\ \text { Florian Diekmann } & \text { Emily Marsh } & \text { Megan Sheffield } \\ \text { Andrea L.Dinkelman } & \text { Alesia McManus } & \text { Laura I. Spears } \\ \text { Diana Farmer } & \text { Nan McMurry } & \text { Suzanne Cady Stapleton } \\ \text { Shannon L.Farrell } & \text { Sarah Milligan } & \text { Sarah C. Williams } \\ \text { Sharon Giovenale } & \text { Carolyn Mills } & \text { Jane Yatcilla } \\ \text { Charlotte Glennie } & \text { Valrie Davis Minson } & \text { Sarah Young } \\ \text { Scott Hanscom } & \text { Jim Morris-Knower } & \\ \text { Inga Haugen } & \text { Mary Ochs } & \\ \text { Liz Holdsworth } & \text { Livia Olsen } & \end{array}$




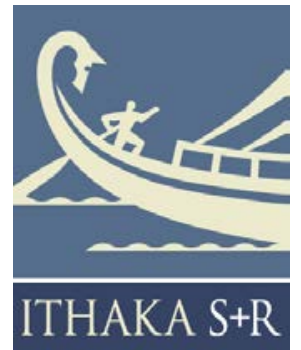

Ithaka $\mathrm{S}+\mathrm{R}$ is a strategic consulting and research service provided by ITHAKA, a not-for-profit organization dedicated to helping the academic community use digital technologies to preserve the scholarly record and to advance research and teaching in sustainable ways. Ithaka $\mathrm{S}+\mathrm{R}$ focuses on the transformation of scholarship and teaching in an online environment, with the goal of identifying the critical issues facing our community and acting as a catalyst for change. J STOR, a research and learning platform, and Portico, a digital preservation service, are also part of ITHAKA.

Copyright 2017 ITHAKA. This work is licensed under a Creative Commons Attribution-NonCommercial 4.0 International License. To view a copy of the license, please see http://creativecommons.org/licenses/by-nc/4.0/.

ITHAKA is interested in disseminating this brief as widely as possible. Please contact us with any questions about using the report: research@ithaka.org. 
We thank $C A B I$ (Centre for Agriculture and Biosciences International) and the United States Agricultural Information Network (USAIN) for their sponsorship of the Research Support Services project on Agriculture.
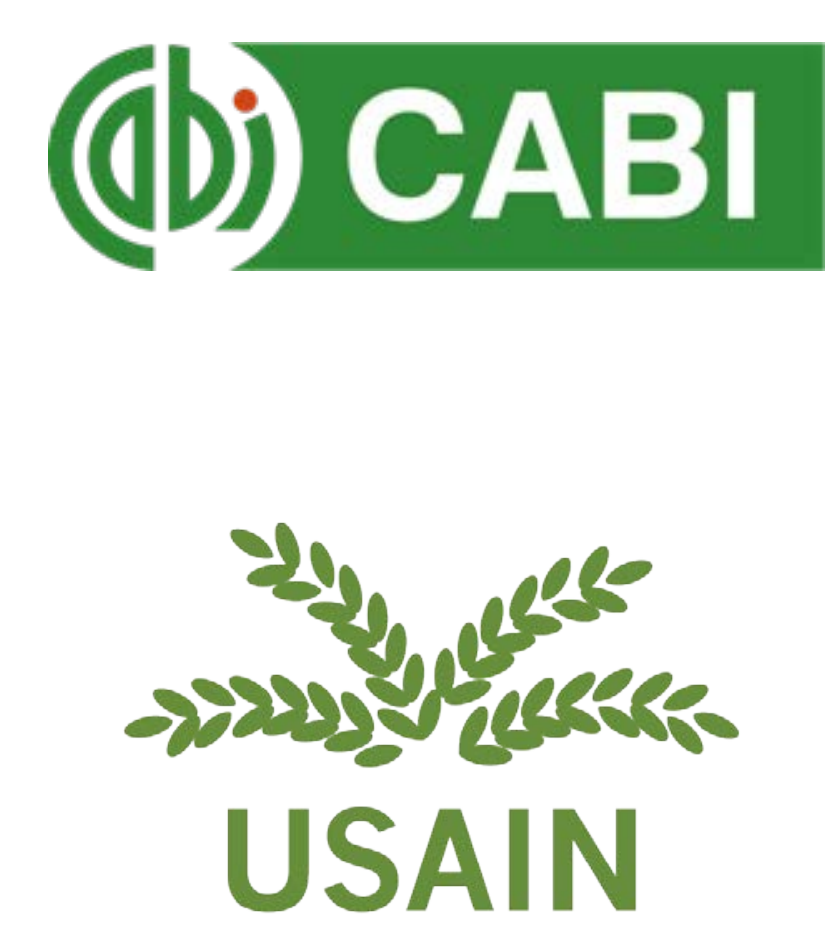

UNITED STATES AGRICULTURAL INFORMATION NETWORK 


\section{Contents}

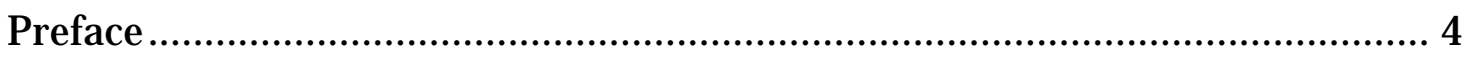

Executive Summary ……….............................................................................

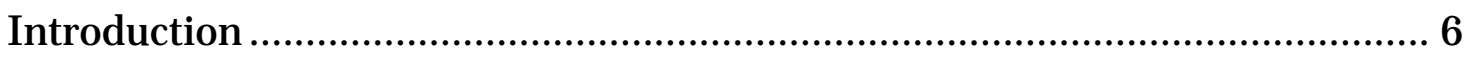

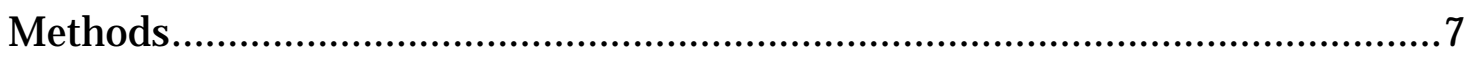

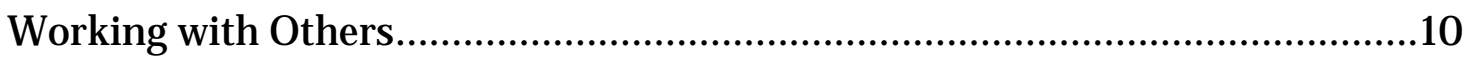

Discovering and Accessing Information............................................................ 11

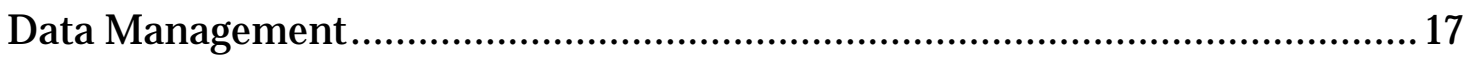

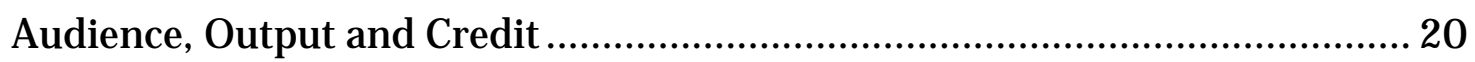

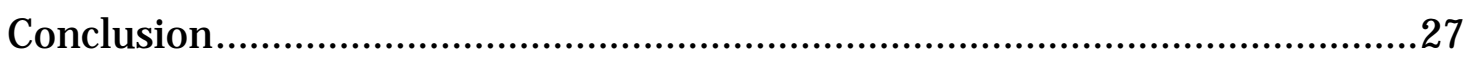

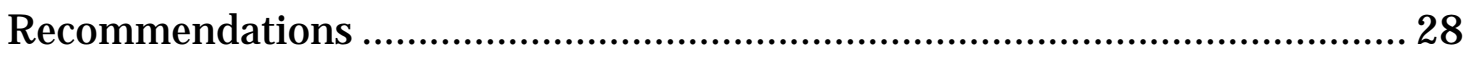

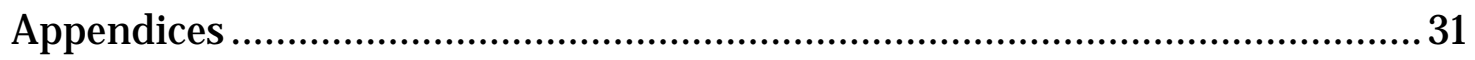




\section{Preface}

For America's land-grant universities, agriculture is a field of bedrock historical importance and vital current relevance. While it is sometimes perceived by the general public as a field to help small farmers modernize, today it also includes advanced genetic research, economic and policy issues around food security, and deep engagement with climate change. As a rich interdisciplinary field at the heart of so many research universities, the practices and needs of agriculture are of interest to many.

For that reason, Ithaka S+R selected agriculture as the latest field to examine in our "research support services" program area, where we study key research practices and identify research support needs that can be addressed by academic libraries and other research information organizations such as learned societies and scholarly publishers. For the field of agriculture, we partnered with 18 academic libraries and the National Agricultural Library, each of which conducted studies of their own affiliated scholars. We are grateful to each of these partners for engaging with us in this project. This report provides Ithaka S+R's overall analysis of the practices and needs of the field.

The field is characterized in part by complex multi-site research teams, constrained research funding, and costly tools and materials. In these respects, it may have certain similarities with medicine (given the plateau in NIH funding and currently discussed cuts) and perhaps the sciences more broadly. For agriculture, scholars reported real needs for help with information management during the course of their research projects (something we have previously observed in the field of chemistry as well) and a need for help translating their findings to reach a broad audience. While the field has broad needs, our recommendations for libraries and other information organizations suggest several specific points of intervention.

Our objective for this project is to help libraries and other information organizations continuously improve their engagement with scholars to support their research practices. Ithaka S+R and its partners have completed similar projects for the fields of history, chemistry, art history, and religious studies. Upcoming projects include public health, Asian Studies, Indigenous Studies, and civil and environmental engineering. We are grateful for the partnerships that have made each of these projects possible. We look forward to hearing your reactions to these findings for the field of agriculture and hope that it is a step forward in helping to support the research in this vital field.

- Roger C. Schonfeld Director, Libraries \& Scholarly Communications Program, Ithaka S+R 


\section{Executive Summary}

Ithaka S+R's Research Support Services Program investigates how the research support needs of scholars vary by discipline. In 2016-2017 Ithaka S+R examined the changing research methods and practices of academic agriculture scholars in the United States, with the goal of identifying services to better support them. The project was undertaken collaboratively with research teams at 19 academic libraries with guidance from an advisory committee.

The goal of this report is to provide actionable findings for the organizations, institutions, and professionals who support the research process of agriculture studies. Two hundred and thirty three scholars were interviewed during the project and Ithaka S+R sampled 95 of the resulting transcripts towards the analysis for this report. These transcripts yielded findings in the following thematic areas in which agriculture would benefit from improved or new services: working with others, discovering and accessing information, information management, and audience, output and credit.

The report concludes by identifying key issues and providing recommendations from across the findings that have wider implications for how agriculture research support is conceptualized and prioritized. Identifying and creating new services is crucial for research support service providers because agriculture scholars position issues pertaining to the information dimension of their research as relatively minor in relation to other challenges such as: coordinating and managing complex research teams and sites, purchasing and maintaining expensive equipment, tools and other materials, and funding research in what agriculture scholars generally characterize as a highly competitive, resource-scarce environment. Agriculture scholars report relatively low challenges with digital discovery and access, particularly in contrast to information management, in which a lack of services and support, coupled with gaps in responsibility, lead scholars to utilize idiosyncratic approaches to the detriment of longterm preservation. While they have a wealth of options for disseminating their scholarship, agriculture scholars struggle with conveying the underlying findings and importance of their research to wider audiences. They perceive this as a significant challenge because of the global importance of agriculture and agricultural issues. 


\section{Introduction}

Ithaka S+R's Research Support Services (RSS) program conducts in-depth qualitative analysis of the research practices and associated support needs of scholars by discipline towards better understanding changing research methods and practices. Our previous projects in the program studied scholars in history, chemistry, art history, and religious studies. ${ }^{1}$ A scholar-centered approach to understanding research in higher education is crucial to developing information services and spaces. A sustained approach to studying different disciplines over time also leads to a better understanding of how research activity functions across the academy.

\section{The field's dynamic scope challenges those engaged with research support services to work across and beyond the boundaries that academic infrastructures often impose on research inquiry to the detriment of innovation.}

Agriculture is a compelling field to investigate research support needs because of its broad and evolving scope, which reflects the centrality of agriculture to the human experience. Technology, societal needs, and environmental pressures are pushing the field to rapidly evolve. The field's dynamic scope challenges those engaged with research support services to work across and beyond the boundaries that academic infrastructures often impose on research inquiry to the detriment of innovation. Reflecting this, agriculture librarianship has a strong history of leveraging collaboration to develop research support services for scholars. ${ }^{2}$ The far-reaching relevance of agriculture is also reflected in the evolving expectations of how agriculture scholars share their research and with whom.

\footnotetext{
1 Jennifer Rutner and Roger C. Schonfeld, "Supporting the Changing Research Practices of Historians," Ithaka S+R, December 10, 2012, http://dx.doi.org/10.18665/sr.22532; Matthew P. Long and Roger C. Schonfeld," "Supporting the Changing Research Practices of Chemists," Ithaka S+R, February 26, 2013, http://dx.doi.org/10.18665/sr.22561; Matthew P. Long and Roger C. Schonfeld," "Supporting the Changing Research Practices of Art Historians," Ithaka S+R, April 30, 2014, http://dx.doi.org/10.18665/sr.22833; Danielle Cooper and Roger C. Schonfeld, "Supporting the Changing Research Practices of Religious Studies Scholars," Ithaka S+R, February 8, 2017, https://doi.org/10.18665/sr.294119.

${ }^{2}$ For examples of how agriculture librarianship community engage in collaborative practices, see the special issue on "Collaboration in Agricultural Librarianship and Information Work," edited by Sarah C. Williams and Christine D'Arpa for Library Trends 63, 3 (2017).
} 
Our report explores agriculture scholars' information activities over the entirety of their research lifecycle from information collection, discovery and access, to organization, preservation, and dissemination, and their perceptions of the key issues facing the discipline and what those issues mean for the evolution of agriculture research. We share our findings and recommendations in order to identify opportunities for the broader community that supports this research.

\section{Methods}

This report is one component of a collaborative research project undertaken with 19 institutions. A central component to developing the project was defining "agriculture" and delimiting meaningful categories within the larger field for further analysis. Attending to representation, both in terms of participating institutions and the scholars included in the research, were also of key concern.

\section{Developing the Agriculture Project}

Ithaka S+R convened a group of advisors who are leaders in their fields to guide the project. We thank Rajiv Khosla (Professor and Assistant Dean, College of Agricultural Sciences, Colorado State University), Amy Paster (Head, Life Sciences Library, Pennsylvania State University) and Ian Maw (Vice President for Food, Agriculture and Natural Resources, Association of Public and Land Grand Institutions) for their thoughtful guidance on the project.

This project is part of Ithaka S+R's ongoing program to conduct research on scholarly information practices by discipline through collaboration with other institutions. ${ }^{3}$ Participation in the project was open to any U.S. higher education institution with an agriculture research program that was able to conform to the project specifications (e.g. timeline, research capacity). We included all institutions that met this criteria, as well as the National Agricultural Library (NAL), whose important and unique role in fostering agriculture research also warranted inclusion. The partner libraries created research teams of one to four members who, following a training workshop designed and led by Danielle Cooper, collected the qualitative data that Ithaka S+R analyzed for this report.

\footnotetext{
${ }^{3}$ Research for our previous reports on the research support needs of scholars in art history, chemistry and history was conducted exclusively by Ithaka S+R staff.
} 
We thank all the institutions that participated in the project. Appendix 1 lists the participants on the institutional research teams. Reflecting the centrality of agriculture to the U.S. land-grant mission established by the Morrill Acts, participation by academic institutions was from public universities. ${ }^{4}$ We regret that we did not achieve participation from historically black colleges and universities and recognize that the unique contexts of these institutions warrant further research for understanding research support needs in agriculture in U.S. higher education.

The research teams at the participating institutions primarily comprised subject librarians but also included participants in other roles such as assessment librarians and graduate students. Each team conducted research with a target of about 15 agriculture scholars at their institution through semi-structured interviews that followed the arc of the research process (see Appendix 3 for the interview guide). Research teams also had the option of using photography to document noteworthy information, collections, and spaces. Each team also developed its own analysis from the data it collected at its respective institution with the option of either creating an internal whitepaper or a publicly available report. The publicly available local reports, which provide a complement to this capstone report, are listed and linked in Appendix 2.

Ithaka S+R collected anonymized transcripts from the 233 interviews conducted across the participating institutions for a total sample of ninety-five interviews towards the analysis for this report. The transcripts were analyzed through a grounded approach to coding utilizing NVivo software. The interviewees remain unidentified in this report to protect anonymity. We thank the interviewees for their participation.

\section{Defining and Delimiting the Agriculture Scholar}

The report focuses on the practices and needs of agriculture scholars in higher education. ${ }^{5}$ Reflecting the project's aim to focus on research as opposed to teaching activities, we defined "scholars" as individuals who are employed by their institutions with research as a significant component of their capacity, as opposed to primarily teaching. Graduate students were also not included in this study. ${ }^{6}$ Scholars affiliated

\footnotetext{
${ }^{4}$ Cornell University is designated as the Land Grant University for New York State, and by extension, its College of Agriculture and Life Sciences is a contract college operated by the university on behalf of the state.

${ }^{5}$ While the report also draws upon insight from interviews collected by the National Agricultural Library on researchers affiliated with that institution, this report does not draw conclusions specifically on their experiences working with that institution, but rather, on their experiences as agriculture scholars more widely.

${ }^{6}$ While research is also a major activity for graduate students, we left graduate students out of scope because the context in which they conduct their research and their relationship to their institutions is different enough to warrant their exclusion.
} 
with extension programs were considered in scope if their institutional role included conducting research.

The definition of agriculture used for this project reflects the breadth and diversity of the field, including food, the environment, natural resources, and international issues. We recognize that the field of agriculture is broad and that researchers fall on a disciplinary spectrum that encompasses the sciences, social sciences, economics, and business. These researchers explore a wide variety of topics including, but not limited to, agronomy, molecular biology, informatics, remediation of soils for production on earth, cellulosic research for biofuels, nutrient enhancements in food, and the human dimensions of working with youth, rural, and urban populations. We also recognize that agriculture is an important mission of many public universities and research in the field can be conducted in partnership with industry, NGOs, and/ or various levels of government.

\section{Scoping the Agriculture Scholar}

Ithaka S+R carefully attended to scholars' methodological orientations to ensure that scholars with a variety of approaches to the field were included in the sample, and that those differences were considered, when relevant, to identifying research support needs and services. Based on discussions with the project advisors, interviews with agriculture scholars were included across the following categories to ensure wide inclusion across the spectrum of agriculture research:

- Agronomy, Soil and Crop Science

- Animal Science

- Economics

- Engineering

- Extension ${ }^{7}$

- Food Science, Nutrition and Technology

- Forest, Natural Resource Management, Wildlife Ecology and Preservation

\footnotetext{
${ }^{7}$ Extension cuts across the other categories, therefore, scholars' work aligned with extension also falls into the other categories included in this list.
} 
- Horticulture

- Human Dimension (e.g. Agriculture Education, Rural Sociology)

- Plant pathology, Entomology and Weed Science

We recognize that this is not a definitive list of all of the permutations of agriculture research and that alternative approaches to categorization can also be helpful. For example, scholars who do work focusing on microbiology, particularly genetic research, display shared research support needs regardless of whether they work with plants or animals. These commonalities are acknowledged, when appropriate, throughout the report.

\section{Working with Others}

The challenges to categorizing agriculture scholars reflects that agriculture research is often a cross-disciplinary and highly collaborative endeavor. Interviewees for this project described conducting research with colleagues in other areas of research within their own agriculture school or a school's extension program, and other national and international institutions. Many described working with scholars in areas of research beyond agriculture, including scholars whose work is oriented towards more "basic" or "applied" pursuits. Collaboration also often takes place with those beyond the academy, such as with individual farmers, breeders and industry partners. As one interviewee highlighted, "we work with epidemiologists, toxicologists, chemists, environmental engineers. They've been at the university level, they've been at the state regulatory level, they've been with industry." This interviewee's comment reflects that agriculture scholars work in different collaborative configurations as their projects warrant.

Agriculture research hinges on working with others in a variety of capacities. Many agriculture scholars work in team-based lab environments where they are overseeing the activities of students, post-doctoral researchers and technicians. Collaborations and partnerships are also necessary for resource and expertise exchange. For example, agriculture scholars may do some of their work in other labs on campus because specialized equipment is housed there or they may rely on other on-campus labs to analyze samples using specialized equipment for them. Another example of collaborative relationships that include agriculture scholars are working groups, which some interviewees described participating in to share knowledge of analytical software and other technologies. 


\section{The cross-disciplinary and collaborative nature of agriculture research has implications for research support across the information lifecycle.}

As the report's findings further explore, the cross-disciplinary and collaborative nature of agriculture research has implications for research support across the information lifecycle. Agriculture scholars desire more streamlined and centralized information discovery experiences, which is more conducive to finding information relevant to their collaborative, cross-disciplinary research pursuits. They also rely on their students to help them discover information and share new techniques for discovering information. Agriculture scholars report challenges with data management because data collection and analysis often involves working with others. At the point of disseminating research, agriculture scholars engaging in cross-disciplinary research encounter a multiplicity of possible venues and work with their collaborators toward determining an appropriate publication strategy. The findings throughout the report attest to the importance of attending to how agriculture scholars work together and with others when developing services for agriculture research support.

\section{Discovering and Accessing Information}

Agriculture scholars have benefitted greatly from improved discoverability of and access to published materials due to digital technologies. These benefits have not, however, been as strong when working with data produced by others. Scholars communicate great interest in using tools that can further help them streamline their discovery of published materials as their work often intersects with and relies on large and overlapping bodies of scientific literature. They often rely on others, particularly students, to assist in information discovery, and by extension, characterize library support of student information as a way of helping them by proxy.

\section{Discovering Published Materials: Seeking Breadth and User Friendliness}

Agriculture scholars increasingly expect streamlined discovery and access points for published materials. Peer-reviewed journal articles represent the majority of published content that agriculture scholars seek. Interviewees report that this content is generally accessible directly to them through institutional subscription and that interlibrary loan programs do a good job of making up any remaining access gaps. They report relying on 
a variety of venues to discover this content, ranging from agriculture and applied science-specific venues (e.g. AgEconSearch , AGRICOLA, CAB Abstracts, PubMed ) to aggregate platforms in the sciences and even more widely (e.g. Web of Science, Scopus, Google Scholar) ${ }^{8}$

Interviewees reported relying on a variety of resources to discover content, often in combination, to ensure full comprehensive coverage across the literatures of various subfields and disciplines they engage with. For example, one interviewee noted, "Web of Science is the one that I start with and after that, I follow that up with CAB Abstracts and AGRICOLA just to catch anything because sometimes those are much more agricultural and they pick up a few things that I don't get in Web of Science." Similarly, another interviewee explained, "I use Web of Science and AGRICOLA. I like to have another maybe two database search engines that I have in my back pocket that I can go ahead and trust like I trust those." Consistent with other disciplines, the library website is not the exclusive or necessarily the first point for discovering content. ${ }^{9}$

Interviewees also highlighted the importance of the user-friendliness of discovery platforms. Several interviewees in particular observed how they have a preference for Google platforms over other platforms due to ease of use. Typical comments included, "What I use less and less is services like [AGRICOLA] and stuff. For whatever reason Google Scholar tends to give me what I want faster, which is really sad"; "I am so used to Google that it's easy to just dive in Google and it directs me, and if I go to Web of Science and others like it's too much information to process"; and, "there are much more advanced platforms out there such as Web of Science that I haven't even, I've barely touched. So I'm not very good at this." Crucially, as these comments reflect, agriculture scholars are more likely to work with easier-to-use discovery platforms, even if they perceive those platforms as not ideal, as opposed to working towards developing their discovery seeking or seeking support from others during the discovery process.

Yet, some others remain steadfast in using platforms that they are more familiar with and believe are better suited to providing relevant content. For example, one interviewee

\footnotetext{
${ }^{8}$ For more information about AgEcon Search see: http://ageconsearch.umn.edu/faq.jsp\#whatisagecon; for more information about AGRICOLA see: https://agricola.nal.usda.gov/help/aboutagricola.html; for more information on CAB abstracts see: http://www.cabi.org/publishing-products/online-information-resources/cab-abstracts/; for more information on PubMed see: https://www.ncbi.nlm.nih.gov/pubmed/; for more information on Web of Science see: http://wokinfo.com/; for more information on Scopus see: https://www.elsevier.com/solutions/scopus; for more information on Google Scholar see: https://scholar.google.com/intl/en/scholar/about.html.

${ }^{9}$ Ithaka S+R's 2015 Faculty Survey found that of four possible starting points for their research, faculty are just as likely to begin with a general purpose search engine as they are with a specific electronic research resource/database and almost as likely to begin with their online library website or catalog. See Christine Wolff, Alisa B. Rod and Roger C. Schonfeld, "Ithaka S+R US Faculty Survey 2015," Ithaka S+R, April 4, 2016, https://doi.org/10.18665/sr.277685, 12.
} 
explained: "I'm a huge fan of Web of Science. That's my favorite. So many people that I've worked with also use Google Scholar. . But I feel like Web of Science finds more relevant information than Google Scholar, and I'm just so familiar with it that that's the one I primarily use. I'll also do random Googling too, just to see what turns up." Returning to the previous finding, the interviewee's comment also highlights that even those who have a marked preference for a particular platform tend to at least incorporate some Google searching into their discovery process to ensure maximum breadth.

\section{Keeping up through Automation and Social Media}

In addition to focused literature searching for specific research projects, interviewees also reported the importance of keeping up with the literature and relevant fields more broadly. Interviewees described a variety of tactics for keeping up and varying levels of discipline and strategy when doing so. Conference attendance was generally reported as important. Some also noted that they regularly browse select journals in their field(s). Other components of academic activity help them keep up to date, such as serving on committees for $\mathrm{PhD}$ admissions or grants. Most notably, many reported, to at least some degree, automating how they receive updates on recently published content as a mechanism for keeping up with research in fields of interest. Most elect to subscribe to particular journals to get notifications on the latest issues with the table of contents, whereas some others receive notifications based on automated keyword results from services such as Pubcrawler. ${ }^{10}$

Social media and networking tools represent an emerging method that agriculture scholars are using to keep up and discover relevant scholarly literature. The social media and networks the interviewees reported engaging with included platforms designed for the general public and platforms designed specifically for academic audiences, such as ResearchGate and Academia.edu. Among scholars who reported using mainstream social media platforms and networks, Twitter was most commonly reported. Interviewees highlighted that they use Twitter both to keep up with individual researchers promoting their work and sharing research and other information of relevance, as well as organizations and agencies, publications, and other media outlets promoting both research and news relevant their research. Interviewees who use Twitter report that its major affordance is the quick dissemination of information. Typical responses included: "It is so rapid. I can take a look, or have it running, you know, on one side while I'm doing something else," and "I do try to keep up with Nature and Science, but I've been finding that more real-time information is more helpful, so following people's Twitter

${ }^{10}$ For more information on Pubcrawler see: http://pubcrawler.gen.tcd.iel. 
feeds is a good way to keep up on what other people are looking at." Scholars who use mainstream social media platforms acknowledge that the information they glean is not comprehensive and therefore cannot be the exclusive source for information discovery. For example, one interviewee explained, "it's not comprehensive but at least I pick up some things." For this reason, another interviewee highlighted that combining discovery systems, including social media platforms, would be ideal for pairing discovery and access: "my dream is to have Twitter, Scoop-It, and a library browser linked altogether, so I have...[all] the stuff I want to read."

\section{Academic social networking can provide a centralized platform for a critical mass of scholars to congregate and help streamline the discovery process.}

Beyond or in lieu of mainstream social media platforms, some interviewees noted that they work with academic social networks. Of those scholars who are engaging with academic social networking the majority reported using ResearchGate. These interviewees highlighted how academic social networking provides benefits over other mechanisms for keeping up, particularly journal notifications. Academic social networking can provide a centralized platform for a critical mass of scholars to congregate and help streamline the discovery process. One interviewee explained how they have a new strategy of searching across various platforms, including ResearchGate, on a semi-regular basis because "in the last couple years I've tried to eliminate as many distractions as possible.. I got rid of all of those table of contents [notifications]." Another interviewee noted: "I like that so many people are using [ResearchGate].. I don't even really look through the table of contents in journals anymore, because you just don't have the time. . It's easier to follow people." As this interviewee's comments also underscore, academic social networking facilitates discovery of information at the author-level and that this level of discovery is just as, if not more useful than discovering information exclusively at the topic-level or by journal, when working to regularly keep up with various fields of interest.

\section{Human Discovery Engines}

Many agriculture scholars reported that they rely on students to discover and retrieve information relevant to their research, particularly published information. Interviewees were far less likely to mention relying on or working with librarians or other individuals 
for information discovery. These students they rely on may be advisees, research and/ or lab assistants, and, while more typically at the graduate level, can also be at the undergraduates.

Some scholars rely on their students primarily for retrieval, such as finding and acquiring requested content through interlibrary loan on a scholar's behalf. Many others, however, noted a discovery component to the information graduate students retrieve for them. In some cases, this information is casually passed on by the student to the scholar due to a shared research interest. More often, however, students are delegated literature review work as part of their participation in a larger research project, and/ or their graduate research thesis or dissertation is connected to their supervisor's research to an extent where their literature review is of strong relevance to their supervisor. When students are effective at seeking information, this dynamic is perceived as beneficial for the scholars. For example, one interviewee explained: "students are always a good source of information because they spend full-time looking at an area, and they're very well aware of the literature. So I get information from students." Another interviewee highlighted: "now I share a grad student with one of my colleagues. . I learned how different the databases are, and how important it is to think about how to search for information. And I learned that through the student." As these comments highlight, there are variety of reasons why scholars perceive delegating literature reviews to their students as beneficial, including that students are more deeply connected to the literature due to the rhythm and expectations of graduate work. Further, students may be aware of or learn approaches to seeking literature that the scholar would otherwise be unaware of.

Due to their reliance on students for information discovery, interviewees for this project also highlighted that students who have poor discovery skills are a challenge for their research. They generally do not perceive that it is their sole responsibility to teach students these skills and often welcome the possibility of others teaching these skills instead. Crucially, while interviewees rarely discussed working with librarians directly to discover information, some did discuss positive experiences with librarians teaching their students to discover information.

\section{Discovering and Using Data Created by Others}

Agriculture scholars rely on a variety of forms of data produced by others, which necessitates discovery and access. This data is used to varying extents depending on agriculture scholars' subfields and research agendas. Patterns of use range from an economist relying on statistical data collected through the USDA's Economic Research Service (ERS) and the Bureau of Labor Statistics, to an engineer collecting data from 
GS1, a not-for-profit barcode generator, to a pathologist working with Global Biodiversity Information Facility, an international open data infrastructure, to access specimen-level data from museum specimen collections on a larger scale. ${ }^{11}$

\section{Opportunities for data discovery lag behind opportunities for discovering other forms of content.}

Some interviewees highlighted how opportunities for data discovery lag behind opportunities for discovering other forms of content. Most notably, the discovery tools for discovering publically available data exist in silos, and discovery tools for published content are inadequate for seeking data that is included within those publications, such as within appendices. In terms of access, state budgetary cuts, which can lead to reductions in what data are collected and made available to researchers. Some interviewees also reported relying on private secondary data that is available for purchase and they cited cost as the major barrier to use. Another ongoing concern is proprietary data produced by private companies that cannot be accessed by researchers or the public, which has implications for the delimiting who "owns" agricultural data, and to what ends such data is used. As one interviewee highlighted, "As more and more data gets privatized what does that mean for people like us trying to actually look at social welfare issues?" This interviewee's question is of increasing concern for agriculture researchers as companies are now embedding analytics tools into their products, which greatly maximizes the amount of data they can collect. 12

A small proportion of agriculture scholars, primarily those who focus on the human dimension of agriculture, also report relying on what is referred to in the humanities and social sciences as "primary sources," such as historical documents, legal documents, and eyewitness accounts. Their experiences discovering and accessing this information is consistent with scholars in other humanities and social science disciplines. Most notably,

\footnotetext{
${ }^{11}$ For more information on GS1, see http://www.gs1.org/barcodes; For more information on Global Biodiversity Information Facility, see http://www.gbif.org/what-is-gbif.

${ }^{12}$ For further discussion of the concerns associated with how proprietary agriculture data is collected using analytics tools, see Kelly Bronson and Irena Knezevic,"Big Data in food and agriculture," Big Data \& Society 3.1 (2016): 1-5.
} 
this content is more challenging to digitally discover and access than secondary published materials. ${ }^{13}$

\section{Data Management}

Managing the data produced from research is an ongoing concern for agriculture scholars. Agriculture scholars create and collect a variety of data types, which are often stored in multiple locations and are difficult to manage and move over time as file formats evolve. A key challenge is the gap in responsibility for who is expected to pay for and oversee data management. The onus largely falls on the researchers themselves, and they lack adequate preparation, policies, training, and infrastructure to do this work. The situation is compounded by increasing expectations by funders for researchers to have data management plans.

\section{Varieties}

The majority of scholars reported that their research involves analyzing data that requires some degree of management. Reflecting the diverse nature of agriculture research, the kinds of data acquired, collected or produced varies widely. The following is a non-exhaustive list of examples of data types, which reflects the variety of data utilized by agriculture scholars:

- $\quad$ DNA and RNA sequencing data

- Metadata about experiments (e.g. lab notebooks)

- Qualitative data (e.g. interview transcripts, ethnographic field notes)

- Quantitative data (e.g. chemical analysis data, census data, consumer data, physiological measurement data, survey data)

- Visual data (e.g. microscopy, mapping, photographic documentation)

Variety in types of data also reflects a variety of data formats and storage needs. The data formats agriculture scholars work with range from numerical data sets stored in spreadsheets, databases, or statistical file formats (e.g. .csv, .sas), to visual information (e.g. micrographs, photographs taken from drones, field plot maps), to written documents, both written by and produced through word processing software. The size of the data sets and their attending storage needs also vary from small data sets, such as

\footnotetext{
${ }^{13}$ For further discussion of challenges working with primary sources in humanistic and social science disciplines, see, for example, Rutner and Schonfeld, "“Supporting the Changing Research Practices of Historians," and Cooper and Schonfeld, "Supporting the Changing Research Practices of Religious Studies Scholars."
} 
excel spreadsheets stored among other content on personal computer hard drive to terabytes of DNA sequencing information stored on autonomous mainframes. With the wide array of information created, collected, and used by agriculture scholars a key issue is whether or not the data produced is perceived as appropriate for sharing beyond those involved in the research. By extension, another key issue is whether there are infrastructures, requirements, and/ or best practices for preserving and sharing the data openly in the long term. The finding, "Shareable Data as an Output" in the later section on "Audience, Output and Credit," goes into further exploration of how agriculture scholars share data.

\section{The Scholar as Reluctant Steward}

Agriculture scholars identify managing data produced while conducting their research as an underlying challenge, which necessitates monitoring and cleaning to prevent mistakes due to either human or machine error. Further errors may also be introduced in a team research structure because multiple people may have access to the data. Data cleaning and monitoring may be delegated to students, post-docs, or lab workers with technical responsibilities; however, delegating these tasks can be challenging because it requires training, managing, and overseeing others to ensure that the standards for accuracy are maintained. As a result, some struggle with managing others and effectively delegating data management tasks. As one interviewee explained, "Each of us [in my lab is] in a rank. You have access up to this point. You have access up to this point. If you have a $\mathrm{Ph} . \mathrm{D}$. research specialist, you have these limits. Everything comes to me...I feel like even after all these years, I'm still the bottleneck of my operation. I'm still the one that has to do all the data cleaning."

Throughout their careers agriculture scholars retain collections of information associated with their research extending beyond the completion of specific projects. Depending on the kinds of data they collect, these may include back-ups of data files, notes, copies of published research materials, and drafts of their writing. This content is typically organized and stored idiosyncratically based on systems devised by the researcher, increasing in complexity and multiplying in size over time as the researcher amasses more content and formats evolve. For some, managing their collection continues to include working with paper. As one interviewee explained, "we still use paper field sheets....Whenever we are out there... typically our practice is to scan them into PDF and digitally archive them...the data is [never going to] be used again." While this interviewee notes that they will likely not use this data again, they expressed that having a back-up is important: "I try to keep digital archives of everything, so I could always go back to it." Another interviewee observed, "If you go into other people's offices, you know the paper starts stacking up. It used to be funny, but the longer you are here, it kind of happens to you. So, it really is I would say more than a number of things, it's really finding this information." This interviewee explained that the pile-up of paper is problematic because it becomes increasingly difficult to find information: "You never know that all of a sudden I start working on this, writing it up, I ran the study two years 
ago, but I am ready to start writing it up, and I've got to be able to find all these different pieces that I ran." As these comments reflect, the efficacy of agriculture scholars' personal information systems depends on their own ability to design and manage them.

In addition to organizing their information collections, storage is also a challenge. Scholars rely on a variety of storage solutions, ranging from personally maintained external hard drives, servers, shared drives, and mainframes, often in combination and designed so that others can have access. As one interviewee elaborated, "we have a few different places [we store data] obviously because bad things can happen." Yet, relying on multiple back-up systems can also lead to confusion about where data and other information resides, especially over time. One interviewee highlighted, "I don't really like having the onus be on me to keep track of all this stuff year after year, but I also don't want it to get lost or anything. And so, now, it's a lot easier now because we have... [cloud storage made available through their institutional affiliation]...where I can put data for long-term storage." As the interviewee explained, this system is preferable because "before, you're putting stuff on hard drives or old computers, and then you get a new one, and then you're loading everything. It's just hard to keep track... [the data from my $\mathrm{PhD}$ ]...was on three computers ago in my Ph.D. lab. And so, I have like a few of the main files that went with the papers, but I don't have everything." While this interviewee's comments reflect that having adequate cloud storage at the institution-level is preferable because it gives scholars one location to store data, responses from other interviewees in this study suggest that adequate institution-provided cloud storage is not yet the norm at all institutions.

Similarly, scholars expressed awareness of and concern for the loss of information associated with faculty retirement. As one interviewee observed "one of the problems that we're having is some of the people that were doing that research are retiring. In fact, last week I went down the hall upstairs and the files from one of our individuals that I'm guessing is getting ready to retire, were sitting up by the recycling bin." Similarly, another interviewee described the following experience when their colleague retired, "one person who actually retired put all his stuff outside the door. After two weeks, they thr[e]w everything away...This guy has things that are important...then somebody's been sending an email, 'Oh, we have his computer. We are going to format it. Anybody needs to get something...' and they format it and then you think, 'Okay, who [has] the responsibility?" While these statements do not convey the extent to which scholars perceive that information collections should be preserved beyond the use of their creators, they do suggest lack of systematic policies and oversight for managing the transition of these collections, including discarding the content. 


\section{Audience, Output and Credit}

Producing peer-reviewed scholarly publications in journals are the primary focus for the majority of agriculture scholars, and their key concern when doing so is choosing the best possible venue among an abundance of possibilities. They are generally supportive of open access models for disseminating published work, and they expressed greatest concern around the cost of making their work openly available through proprietary publishing venues. For some agriculture scholars the data they produce can be considered another form of shareable output, and systems of tenure and promotion have not caught up to recognize these contributions to scholarship. Other kinds of research outputs, largely in conjunction with work with research centers, extension programs, and/ or other industry collaborations, also represent another area of meaningful agriculture research output activity. Digital media is opening up new venues for communicating this work, however, general use of these affordances remains relatively low.

\section{Choosing Among Peer-Reviewed J ournals}

The majority of agriculture scholars report peer-reviewed scholarly journal articles as the main output resulting from their research. They rarely disseminate their scholarship through other forms of peer reviewed publications, such as monographs and book chapters. Interviewees also contend with an abundance of possible venues to submit their work due to the cross-disciplinary and collaborative nature of their research. When determining which peer reviewed journals to publish in, interviewees noted that there are a number of concerns, some overlapping, that must be taken into account.

With this abundance of choice among peer-reviewed journals, agriculture scholars typically consider whether a venue has the "right audience" or "where [the article] will be most useful" when determining where to publish. Many reported making decisions on a project-by-project and publication-by-publication basis, in part, based on consideration of their collaborators' preferences. Some also noted that they deliberately use varying venues so that their research can be shared among both narrower and broader audiences. For example, one interviewee who specializes in viticulture within horticulture explained, "The J ournal Oenology and Viticulture is good because it is as the name suggests a very specific journal. But the American Society for Horticultural Science has three journals and we've published in two of those over the years and that allows us - at least in my way of thinking it brings us into maybe a little broader contact with other horticulturists and not necessarily viticulturists." Similarly, another interviewee who focuses on plant genomics stated: "you can do a very clearly delineated genetic study that's elegant and does stuff, but there's going to be, like, 10 people [who] will read it. Then there's other things that have broader implications... [where] we try to push it into the best journals. It's like we've had things in a Science and Nature, but we've also, like PNAS, but we also publish in sort of Aggie journals like Crop Science or Molecular 
Breeding or things like that.. I guess it depends where we feel the information is most useful for the user community."

Impact factor was also cited as a consideration beyond audience and scope, however, there was less consensus among scholars about the importance of such metrics. Some scholars reported focusing their output activity on publishing in journals with the highest possible impact while many others, at the very least, displayed some awareness of various impact factors among journals they are familiar with. Many interviewees highlighted that impact factor is not the exclusive consideration for determining where to publish because journals in agriculture research tend to be lower impact due to agriculture's status as applied research.

In lieu of impact, these respondents typically reported that the metrics for tenure and promotion for agriculture researchers include the volume of publications, general reputation of the journals in which they publish, and author status (e.g. first or last author). By extension, speed and relative ease of turn-around is generally valued by researchers because it leads more publication credits. ${ }^{14}$ As one interviewee offered as an example of how the dialogue and deliberation likely transpired during their own tenure review: "'Oh, [they have] published a first-and-last author paper, that's good, it means it's [their] research.. and [they've] published in some good ones and some bad ones'...what they'll do is they'll say, 'six [publications] in Crop Science, that's excellent,' and then they won't look at the impact factor, because I'm an agricultural person." Some interviewees highlighted, however, that they perceive that impact is increasingly important in grant seeking, hiring, and tenure and promotions processes in agriculture. In this changing climate, some reported struggling with articulating the value of their work to tenure and promotion committees.

\section{Cost Considerations}

Cost is also a consideration when choosing a journal venue and whether or not to make a publication available through open access. Some interviewees highlighted how the page costs charged for publishing with society journals can be prohibitively expensive and observed that some journals were now lowering or eliminating those charges to attract authors. Some continue to publish with society journals, despite the cost and relative lack of ease in the submission process in comparison to proprietary venues, because they

\footnotetext{
${ }^{14}$ Despite this, interviewees rarely mentioned a need for or interest in a developing more robust preprint publishing culture in agriculture. The issue of speed and relative ease of turn-around was more likely discussed by interviewees when debating the relative merits of proprietary journals versus journals produced by scholarly societies, with some noting that proprietary journals offer a more seamless submission experience. Perceptions may shift with the introduction of AgriXiv, an open source preprints service developed by the Center for Open Science (COS). AgriXiv launched in February 2017, which was after the interviews for this project were conducted. For more information about AgriXiv, see: https://cos.io/about/news/center-open-science-releases-preprint-service-agrixiv/.
} 
perceive it as important to support the societies. As one interviewee noted, "I had some colleagues that were bemoaning the fact that our professional society still has page charges. . and my answer is, I'm going to support my society as much as I can, I can still afford to do it, so I'm going do that because that to me is the main audience that I'm directing it towards."

The issue of cost also factors into interviewees' approach to making their peer-reviewed publications available via open access. When asked about whether their publications are available via open access, many interviewees focused on the cost of gold open-access models. ${ }^{15}$ These interviewees highlighted that while they are generally supportive of open access, the cost of making their articles open access through the journals they publish in is prohibitively high, especially since they are expected to publish multiple articles per project and per year. A typical response by an interviewee: "I am all for the open access. That's good but I have mixed feelings because you have to pay to get your paper published... That's a lot of money and my lab can publish around twenty papers a year. I tell my students to please find a free journal. If it is open access where is my money?" Some had built those costs into their grants or had qualified for funds made available for that purpose by their institution, but others noted that money is already such a concern that they didn't perceive it as prudent to allot costs towards open access or that institutional funds were not available. As the same interviewee highlighted, "Yes you can use grants to get it published, but you have to make the cuts somewhere else to make it work. ...When I first came the department would pay for publication but now the department cannot afford it."

Interviewees rarely reported deliberately seeking out green open access peer-reviewed publications, which reflects that other considerations such as reputation and scope are generally more important. Interviewees also reported low participation in their institutional repositories as a mechanism for making their publications open access, with some being unaware of such programs or perceiving the participation as too onerous. Some recognize that they may be required in the future to deposit their publications in an appropriately designated repository as a condition of receiving government funding, but the majority had not yet experienced such a requirement. Those who have reported that they deposited did so because non-agriculture-specific agencies, such as the National Institute of Health, required it. Others conflated open access and institutional repositories with academic social networking sites (discussed in further detail below).

\footnotetext{
15 "Gold" open access generally refers to open access journals, regardless of business model whereas "green" generally refers to open access repositories. For further information, see Peter Suber, Open Access (Cambridge: MIT Press, 2012), 175.
} 


\section{Outputs beyond Peer-Reviewed J ournal Publications}

Agriculture scholars also report developing a variety of outputs from their research beyond peer reviewed journal publications, including conference presentations and proceedings, invited talks and workshops, industry and trade publications, technical reports, and extension bulletins, videos and factsheets. Conference presentations and proceedings may also be peer-reviewed and, while secondary in value to peer-reviewed journal publications for tenure and promotion, are still generally considered central to scholarly output activity. Beyond those outputs, the major variable for scholars in determining the volume and nature of their research output activity is based on the extent to which they collaborate with or for industry partners and/ or have extension appointments in which they receive credit for producing extension-based outputs. Scholars reported relatively few challenges in producing outputs in collaboration with or for industry partners.

Beyond publishing in gold open-access peer-reviewed journals, respondents reported that their extension-based outputs are frequently made freely available. This information is often made directly available through extension program websites, personal websites, and through platforms for hosting content, such as YouTube. It was rare for agriculture scholars to report producing extension-based outputs unless they held formal appointments in an extension program.

For those who produce extension-based outputs, an ongoing consideration is effectively disseminating information and developing communication lines with community stakeholders. These endeavors can be especially challenging in rural contexts where populations are diffuse. For some, social media is perceived as an opportunity to broaden the reach of extension outputs. Others also reflected on the relative reach of extension materials and the need to communicate the value of agriculture even more broadly to the general public. As one interviewee explained, "[there are] extension bulletins but not everybody reads that material. So we need to have other outlets. You know, whether that be Twitter or, you know, I don't know, websites or whatever. But I've been doing - I'm on Twitter partly for that reason."

\section{Agriculture scholars perceive their work as having a wider value but are ambivalent about whose role it is to translate and communicate that value to the wider public.}

In addition to the reach of extension-related content to extension stakeholders, agriculture scholars are also concerned about the lack of wider public awareness of their research. They recognize that this issue is caused in part due to both the challenges 
communicating the value of insights from their agriculture research to the public and the challenges communicating the broader importance of agriculture to the public. As one interviewee explained, "the biggest challenge is communication to the non-agricultural public. You know, the importance of agriculture which is, like, we want to eat isn't communicated well and so that there's a big disconnect. Still, agriculturalists always talk about the importance." However, interviewees typically identified this as a broader societal issue as opposed to identifying this as a personal challenge that they had interest in rectifying through their own research activities. Agriculture scholars perceive their work as having a wider value but are ambivalent about whose role it is to translate and communicate that value to the wider public.

\section{Shareable Data as an Output}

Beyond outputs requiring synthesis and reflection of research, some agriculture scholars perceive that data produced in the process of conducting research can constitute a research output if it can be disseminated to and used by others, either in a raw form or through the result of some processing. This perception is different to but often accompanied by other motivations for depositing data, such as requirements by funders or journals, and preservation. Scholars who perceive their shareable data as an output typically belong to larger research communities that rely on a culture of data sharing and already have infrastructure(s) to support sharing. This was most commonly reported by those who engage in genetic sequencing work. These scholars reported some variety in platforms available for sharing data ranging, such as those geared to genetic research more broadly (e.g. platforms developed by the National Center for Biotechnology Information such as GenBank, Gene Expression Omnibus) and organism or commodityspecific databases (e.g. Gramene, the Genomic Database for Rosaceae). ${ }^{16}$

For scholars who perceive their data sharing as an output, a major challenge is that this work is not recognized and rewarded accordingly. As one interviewee explained, "how they reward our academic productivity, a genome sequence is not counted unless there is a paper associated with it. . it would be just better to value the product per se than forcing people to, to go back then to the traditional academic product." Another interviewee highlighted how developing processes of recognition for data deposits is important for encouraging greater sharing: "There's talk about. . having those databases be a citable entity...you would essentially publish a database without maybe any interpretation, just the metadata. And there's a lot of value in that for the broader community." Researchers

\footnotetext{
${ }^{16}$ Further information about GenBank can be found here: https://www.ncbi.nlm.nih.gov/genbankl; further information about the Gene Expression Omnibus (GEO) can be found here: https://www.ncbi.nlm.nih.gov/geo/; further information about Gramene can be found here: http://www.gramene.org/; further information about the Genomic Database for Rosaceae can be found here: https://www.rosaceae.org/.
} 
sometimes choose to accompany their deposits with a journal publication in the form of a short announcement describing the research process with little to no accompanying analysis; however, these announcements are also not typically peer reviewed.

Beyond genetic-related shareable databases, a small group of scholars reported engagement or awareness of Dryad, which is designed as a repository for the data collections associated with publications across the sciences. ${ }^{17}$ Some who had used or explored Dryad for depositing their data reported the cost of depositing as a barrier. ${ }^{18}$ One interviewee made the following comment about being required to deposit their data in Dryad in the process publishing an article with the journal Heredity: "you have to buy that space on Dryad basically, which is kind of a back door increase to the publication cost. It's not an increase to Heredity; it's an increase to us. So that's just like you're paying Heredity so much to publish, and now you're paying Dryad so much to keep it on Dryad." These scholars' comments echo the concerns agriculture scholars make about other costs associated with publishing discussed earlier in this section, most notably through page charges and gold open access fees.

Those who reported that they do not regularly share their data provided a variety of reasons why they did not do so, often in tandem. Some noted that their research either does not produce enough data to warrant sharing or that the raw data would not be meaningful to other researchers. For example, one interviewee who is a horticulturist explained, "the molecular people are always trying to put the gene sequences in the gene banks and do those kind of things on the molecular side. I don't know of any over here like in the sciences that would be interested in my extra data." Some scholars also noted that they collect data that would be logistically difficult to put into a shareable form. As one interviewee explained, "I'm the only one who can figure out what [the data] really means, because it's 200 sensors in many trees, it's difficult to decipher. And it took me, it's taken me like two months to write a program to analyze it." Others suggested that it would not be worthwhile to deposit, either because their focus is on publishing (e.g. "My goal is to publish. I run the research and publish. If I publish then I figure that that information is out there") or the effort is not worth the lack of reward (e.g. "I have yet to see the cost or benefit ratio of it."). In lieu of using a data-sharing specific platform, some interviewees discussed alternative methods to making their data available, such as publishing data as an addendum or through supplemental files to their peer-reviewed

\footnotetext{
${ }^{17}$ For more information about Dryad, see http://datadryad.org/pages/organization.

${ }^{18}$ Dryad operates as a not-for-profit and charges a Data Publishing Charge (DPC) to offset the cost of the service. At the time of writing this report, the charge was $\$ 120$ per data package, and could be waived for some authors based on country of origin. Some organizations and publications also cover the DPC charge for authors. For more information see: https://datadryad.org/pages/payment.
} 
publications, making the data available through their own channels (e.g. via a lab websites), or having a willingness to consider sharing their data with researchers who contact them directly.

\section{Reaching out through Digital Media Sharing Platforms and Social Networking}

Some agriculture scholars also disseminate information pertaining to their research through engagement with platforms that disseminate digital media sharing and facilitate social networking. However, more scholars reported not regularly engaging with such platforms and/ or had criticisms of those platforms. Typical criticisms included skepticism that these platforms are meaningful ways to communicate research findings, challenges keeping up profiles, and critiques of the ability of platforms to create meaningful networks.

Interviewees who reported engaging with digital media sharing and social networking platforms mentioned both mainstream platforms (e.g. Twitter, Facebook, YouTube) and platforms designed explicitly for academic networks (e.g. ResearchGate, academia.edu). Interest and engagement with disseminating research through social media is reflective of agriculture scholars' perceptions about the importance of agriculture information to various publics beyond academia. As one interviewee highlighted, "Technology is really important for getting your message out to as many people as possible with social media... I think one of the best ways for the farmers is using something like YouTube and having videos. And that's why we have about 250 videos on the website." Another interviewee also noted, "I would say that nowadays a lot of people are trying this kind of cross pollination technique where you take things out of peer reviewed publication and try to translate that down to the general public. . almost all of our faculty here have Facebook pages for their programs."

Another useful feature of digital media sharing and social networking platforms is that they can promote loci of agriculture research activity, such as labs, extension programs, or on-campus research centers. An example of responses reflecting this kind of activity include: "We have a lab Facebook and an Instagram, and we put all of our news blasts and announcements through there,"; "we do a lot with the Water Center, and information transfer and social media. Like we'll take this article, because it is open access and post it, and you know and do a little blurb on Facebook and then we'll pay 10 bucks to boost its [ranking]..."; "I put links to it on my page and all of the Facebook pages that I manage from the ornamental plant breeding program lab. There's a link to my page and if you happen upon it then you can get all of the work that we do." These tasks may be shared or delegated among various project or center affiliates, including graduate 
student assistants. Other forms of digital dissemination, most notably lab or extension websites or blogs, continue to be used in tandem.

Beyond mainstream digital media platforms, some scholars reported engaging with social networking platforms specifically designed for academic purposes. More scholars reported engaging with ResearchGate rather than academia.edu, but there is some ongoing skepticism and ambivalence as to whether this will continue to be the dominant platform. While one interviewee commented, "So, I'm now, you know, on ResearchGate.. It seems like that's, kind of, sweeping through everybody and everything right now... So, I have my papers uploaded through them," another noted, "I very grudgingly keep a semi updated ResearchGate page because I do find that that's actually useful... I think there's visibility there. Lately it does seem to have petered." In this complicated landscape, some report using various platforms simultaneously: "for the PDFs, I usually put it on... ResearchGate, make them accessible there, which I really used to like... [but] currently I'm kind of drifting more towards Google Scholar." Academic social networking platforms can also be used in conjunction with mainstream digital media for greater impact.

\section{Conclusion}

In the landscape of currently existing research support available for agriculture scholars, supports for information discovery are far more robust than those offered for information management, and this is reflected in what agriculture scholars perceive as the painful and painless elements of their research. Across the sub-fields of agriculture, agriculture scholars have benefitted in particular from digital discovery mechanisms for published materials when conducting focused searches for their research, and they often use automated processes to keep up with the literature on a regular basis. However, they continue to distrust that any one platform or tool can provide comprehensive discovery. They have a preference for streamlined, centralized opportunities for discovery and are more likely to rely on their colleagues, collaborators, and students than information professionals for support in these processes. Agriculture scholars may also rely on data produced by others and there are huge variations in how this data can be discovered and accessed.

Information management, particularly data management, is a central component to agriculture scholars' research, and these activities have much fewer tools and services to support these endeavors in contrast to information discovery. Agriculture scholars report relying on idiosyncratic methods for organizing and storing the data and other information associated with their research. Funding and institutional requirements around data management plans are not sufficient solutions because there is often little to no oversight over implementation, requirements vary widely, and only pertain to specific projects as opposed to covering the lifecycle of the researcher. Supporting the 
information management activities of agriculture scholars over the course of their careers represents a major opportunity for developing new research support services.

\section{While there is extreme diversity in the kinds of research that agriculture scholars conduct, agriculture scholars strongly agree about the underlying value of their work to the general public.}

While there is extreme diversity in the kinds of research that agriculture scholars conduct, agriculture scholars strongly agree about the underlying value of their work to the general public. They report a clear desire for the public to have a stronger awareness of findings from agriculture research and the importance of that work. Many interviewees also identified the lack of awareness of agriculture research by the public as one of the grand challenges facing the field, which has implications for the degree to which agriculture research is funded and how research is used to shape public policy.

There is a large disconnect between agriculture scholars' perception that their research is widely valuable and the opportunities for that value to be communicated. Tenure and promotion systems reward scholars for publishing in peer-reviewed publications and the costs for making these publications publically available, the most common form of open access in the field, represents a major cost offloaded onto authors. Communicating with the general public is not rewarded, nor do scholars receive training in developing these forms of outputs. Furthermore, the scholars themselves do not necessarily perceive it as their role to directly communicate with the public.

\section{Recommendations}

\section{Discovering and Accessing Information}

- Streamline and simplify information discovery platforms. Agriculture scholars prefer easy-to-use discovery platforms and seek opportunities to consult as few platforms as possible; however, they continue to rely on multiple platforms because of content gaps.

- Develop and promote best practices for discovering information through automation and social media. Agriculture scholars rely on tools and services to keep up with the literature in their field, and social media is emerging as a preferred approach.

- Focus on training students in information discovery and retrieval. Agriculture scholars rely on their students to discover and retrieve other published content related to their 
research but they are also concerned about their students' abilities to do so. Agriculture scholars perceive that they are not solely or even primarily responsible to provide this training and are receptive to that training being provided by others, including those affiliated with their institution's library.

\section{Information Management}

- Educate scholars on best practices for organizing and preserving their information. Agriculture scholars are responsible for maintaining information collections for their present use and over the course of their careers, often in a variety of formats that evolve over time. They largely design and maintain these collections independently and idiosyncratically, for which they currently receive minimal to no oversight or training from those with expertise in information management.

- Develop digital storage services that are responsive to scholars' needs. Many agriculture scholars rely on a patchwork system of different storage solutions as a mechanism for ensuring they have adequate space and back-ups, however, such systems are challenging for tracking and maintaining collections in the long term. Digital storage services for agriculture scholars must provide adequate space, support for ensuring appropriate mechanisms for preservation, and reflect that scholars may not have the same institutional affiliation over the course of their careers.

- Partner with scholars and departments to improve transitions for personal information collections. Agriculture scholars often do not have plans for their personal information collections for the long term beyond their own use. Consistent policies and programs for appraising information collections that scholars will no longer be personally maintaining, will lead to more systematic approaches to determining which information should be discarded and retained, and by whom.

\section{Audience, Output, and Credit}

- Develop and strengthen services to help faculty articulate the value of their publications. The metrics of evaluating publications towards tenure and promotion are in flux, warranting support for effectively articulating the value of research, including through alternative metrics.

- Improve the features and functionality of society journals. Authors view current page charge schemes in society journals negatively because they do not perceive that they are receiving adequate value in return, particularly in comparison to their experiences publishing in proprietary venues. Improved functionality in the discovery and submission process and other features, such as automatic open access or waiving page charges based on frequency of reviews, may help better justify page charges.

- Advocate for and create mechanisms for recognizing and rewarding data sharing when appropriate. In some areas of agriculture research, most notably genetics, shareable data is incredibly important to the culture and pace of field advancement. Systems of reward through grants, tenure and promotion have not yet been brought into alignment to 
recognize these contributions. Best practices must also be established so that data sets can be discovered across platforms and cited accordingly to promote and credit their use.

- Create best practices and infrastructures for effectively communicating agriculture research to the public. Agriculture scholars are aware of and concerned by low public awareness of agriculture research and agriculture more broadly, however, they are not in a structural position to improve public awareness on their own. Digital media platforms and social networking have the potential to strengthen public communication channels and scholars need considerable support to translate their work through these mediums. 


\section{Appendices}

\section{Appendix 1: Participating Research Teams}

1. Auburn University: Claudine Arnold J enda

2. Clemson University: Megan Sheffield

3. Cornell University: Camille Andrews, Ashley Downs, J im Morris-Knower, Mary Ochs, Sarah Young

4. Kansas State University: Diana Farmer, Livia Olsen

5. National Agricultural Library: Scott Hanscom, Adam Kriesberg, Emily Marsh, Cynthia Parr

6. Oklahoma State University: Hui-Fen Chang, Sarah Milligan

7. Oregon State University: Hannah Gascho Rempel, M. Brooke Robertshaw

8. Purdue University: Marianne Stowell Bracke, J ane Yatcilla

9. Texas A\&M University: Sarah Bankston, J enni Simonsen

10.The Ohio State University: Florian Diekmann

11. University of Arkansas: Marei Houpert, Necia Parker-Gibson

12. University of California, Davis: Beth Callahan, Charlotte Glennie, Alesia McManus

13. University of Connecticut: Sharon Giovenale, Carolyn Mills

14. University of Florida: Valrie Davis Minson, Laura I. Spears, Suzanne Cady Stapleton

15. University of Georgia: Liz Holdsworth, Nan McMurry

16. University of Illinois Urbana-Champaign: Erin Kerby, Sarah C. Williams

17. University of Minnesota: Shannon L. Farrell, Megan Kocher

18. University of Nebraska - Lincoln: Leslie M. Delserone, Andrea L. Dinkelman

19. Virginia Polytechnic Institute and State University: Inga Haugen 


\section{Appendix 2: Local Reports}

While all participating institutions created reports based on the data and analysis conducted locally, the participants were given the option whether or not to disseminate their reports publicly. The following reports are publicly available:

Andrews, Camille; Young, Sarah; Ochs, Mary; Shea, Ashley; Morris-Knower; J im. “Final Report: Research Practices and Support Needs of Scholars in the Field of Agriculture at Cornell University." Cornell University, 2016.

https:// ecommons.cornell.edu/ handle/ 1813/45090.

Callahan, Beth; McManus, Alesia; Glennie, Charlotte. "Research Support Services: Agriculture." University of California, Davis, 2016.

http:// escholarship.org/uc/item/ 7qr1h8ws.

Chang, Hui-Fen and Milligan, Sarah. "TTHAKA S\&R research report services: Prospectus for the field of agriculture: Oklahoma State University Library local report." University of Oklahoma, 2016, https:// shareok.org/ handle/ 11244/47160.

Delserone, Leslie M. and Dinkelman, Andrea L. "Investigating the Practices and Needs of Agricultural Researchers at the University of Nebraska-Lincoln." University of NebraskaLincoln, 2016. http:// digitalcommons.unl.edu/libraryscience/341.

Farrell, Shannon L. and Kocher, Megan. "Examining the Research Practices of Agricultural Scholars at the University of Minnesota - Twin Cities." University of Minnesota, 2016. http:// conservancy.umn.edu/ handle/ 11299/ 183471.

Hanscom, Scott; Kreisberg, Adam; Marsh, Emily; and Parr, Cynthia. "Agricultural Researcher Support Services: A Study Conducted by the National Agricultural Library in Cooperation with Ithaka S+R." National Agricultural Library, 2017. https:// www.nal.usda.gov/sites/default/files/ithaka_report_with_logo_revised.pdf.

Haugen, Inga. "17 Interviews with Virginia Tech CALS Faculty: State of Research and How Information Professionals Can Help.” Virginia Tech, 2016.

https://vtechworks.lib.vt.edu/handle/ 10919/73585.

J enda, Claudine Arnold. "Research Practices and Support Services in Agriculture at Auburn University." Auburn University, 2016. http:// hdl.handle.net/ 11200/48808.

McMurry, Nan and Holdsworth, Liz. "Research Support Services for Agriculture." University of Georgia, 2017. http:// athenaeum.libs.uga.edu/ xmlui/handle/ 10724/36545. 
Mills, Carolyn V. and Giovenale, Sharon. "Research Support Study: Agriculture; University of Connecticut Local Report." (2016). University of Connecticut, 2016, http:// digitalcommons.uconn.edu/libr pubs/57.

Olsen, Livia M.S. and Farmer, Diana. “Research Support Services: Agriculture.” Kansas State University, 2016. http:// hdl.handle.net/ 2097/34585.

Parker-Gibson, Necia T. and Houpert, Marei U. "Research Support Services for the Field of Agriculture: Semi-structured Interviews." University of Arkansas, 2016. http:/ / uark.libguides.com/ c.php?g=589516.

Rempel, Hannah Gascho and Robertshaw, M. Brooke. "Supporting the Research Practices of Agricultural Scientists: Oregon State University's Ithaka Report." Oregon State University, 2016. http:// hdl.handle.net/ 1957/ 59997.

Sheffield, Megan. "Research Support Services in Agriculture.” Clemson University, 2016, http:// tigerprints.clemson.edu/lib pubs/131/.

Stapleton, Suzanne; Minson, Valrie; Spears, Laura. "Investigating the Needs of Agriculture Scholars: Findings from the University of Florida." University of Florida, 2016. http:// ufdc.ufl.edu/IR00009135/00001.

Williams, Sarah C. and Kerby, Erin E. "Tthaka S+R Agriculture Research Support Services Study: University of Illinois at Urbana-Champaign Report." University of Illinois at Urbana-Champaign, 2016. http:// hdl.handle.net/ 2142/94839.

Yatcilla, J ane and Stowell Bracke, Marianne. "Investigating the Needs of Agriculture Scholars: The Purdue Report for Ithaka S+R." Purdue University, 2016. http:// docs.lib.purdue.edu/lib fsdocs/165/. 


\section{Appendix 3: Interview Guide}

Research focus

- Describe your current research focus and how this focus is situated within the broader agriculture discipline and the academy more broadly. [Probe for whether/ not they see themselves as located firmly within agriculture as a discipline or located across/ between disciplines]

Research methods

- What research methods do you currently use to conduct your research?

- What kinds of data does your research typically elicit?

- How do you locate the primary and/ or secondary source materials you use in your research?

- Think back to a past or ongoing research project where you faced challenges in the process of conducting the research.

- Describe these challenges.

- What could have been done to mitigate these challenges?

- How do you keep up with trends in your field more broadly?

Dissemination Practices

- Where do you typically publish your research in terms of the kinds of publications and disciplines? How do your publishing practices relate to those typical to your discipline?

- Have you ever deposited your data or final research products in a repository?

- If so, which repositories and what has been your motivations for depositing? (i.e. required, for sharing, investment in open access principles)

- If no, why not? 
Future and State of the Field

- What future challenges and opportunities do you see for the broader field of agriculture?

- If I gave you a magic wand that could help you with your research and publication process - what would you ask it to do?

Follow-up

- Is there anything else about your experiences as a scholar of agriculture and/ or the agriculture discipline that you think it is important for me to know that was not covered in the previous questions? 